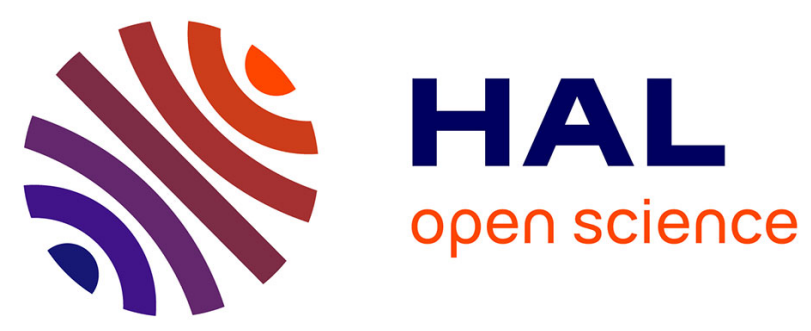

\title{
Anatomical and molecular consequences of Unilateral Naris Closure on two populations of olfactory sensory neurons expressing defined odorant receptors
}

Adrien Molinas, Imad Aoudé, Vanessa Soubeyre, Bassim Tazir, Hervé Cadiou, Xavier Grosmaitre

\section{To cite this version:}

Adrien Molinas, Imad Aoudé, Vanessa Soubeyre, Bassim Tazir, Hervé Cadiou, et al.. Anatomical and molecular consequences of Unilateral Naris Closure on two populations of olfactory sensory neurons expressing defined odorant receptors. Neuroscience Letters, 2016, 626, pp.42-47. 10.1016/j.neulet.2016.05.027 . hal-01390882

\section{HAL Id: hal-01390882 \\ https://u-bourgogne.hal.science/hal-01390882}

Submitted on 26 Sep 2017

HAL is a multi-disciplinary open access archive for the deposit and dissemination of scientific research documents, whether they are published or not. The documents may come from teaching and research institutions in France or abroad, or from public or private research centers.
L'archive ouverte pluridisciplinaire HAL, est destinée au dépôt et à la diffusion de documents scientifiques de niveau recherche, publiés ou non, émanant des établissements d'enseignement et de recherche français ou étrangers, des laboratoires publics ou privés. 
Research paper

\title{
Anatomical and molecular consequences of Unilateral Naris Closure on two populations of olfactory sensory neurons expressing defined odorant receptors
}

\author{
Adrien Molinas, Imad Aoudé, Vanessa Soubeyre, Bassim Tazir ${ }^{1}$, Hervé Cadiou ${ }^{2}$, \\ Xavier Grosmaitre* \\ Centre des Sciences du Goût et de l'Alimentation, CNRS, INRA, Univ. Bourgogne Franche-Comté, F-21000 Dijon, France
}

\section{H I G H L I G H T S}

- The density of MOR23 and M71 olfactory neurons is affected differently by UNO.

- UNO modulates transduction pathway transcripts levels at the cellular level.

- Effects of UNO will have consequences on odorant coding properties of OSNs.

\section{A R T I C L E I N F O}

\section{Article history:}

Received 24 March 2016

Received in revised form 29 April 2016

Accepted 13 May 2016

Available online 14 May 2016

\section{Keywords:}

Main olfactory epithelium

Sensory deprivation

Anatomy

Expression levels

Odorant receptor

Transduction proteins

\begin{abstract}
A B S T R A C T
Mammalian olfactory sensory neurons (OSNs), the primary elements of the olfactory system, are located in the olfactory epithelium lining the nasal cavity. Exposed to the environment, their lifespan is short. Consequently, OSNs are regularly regenerated and several reports show that activity strongly modulates their development and regeneration: the peripheral olfactory system can adjust to the amount of stimulus through compensatory mechanisms. Unilateral naris occlusion (UNO) was frequently used to investigate this mechanism at the entire epithelium level. However, there is little data regarding the effects of UNO at the cellular level, especially on individual neuronal populations expressing a defined odorant receptor. Here, using UNO during the first three postnatal weeks, we analyzed the anatomical and molecular consequences of sensory deprivation in OSNs populations expressing the MOR23 and M71 receptors. The density of MOR23-expressing neurons is decreased in the closed side while UNO does not affect the density of M71-expressing neurons. Using Real Time qPCR on isolated neurons, we observed that UNO modulates the transcript levels for transduction pathway proteins (odorant receptors, CNGA2, PDE1c). The transcripts modulated by UNO will differ between populations depending on the receptor expressed. These results suggest that sensory deprivation will have different effects on different OSNs' populations. As a consequence, early experience will shape the functional properties of OSNs differently depending on the type of odorant receptor they express.
\end{abstract}

(c) 2016 Elsevier Ireland Ltd. All rights reserved.

\footnotetext{
* Corresponding author at: Centre des Sciences du Goût et de l'Alimentation, UMR 6265 CNRS - Université de Bourgogne-Franche-Comté - UMR1324 INRA, 9E boulevard Jeanne D’Arc, 21000 Dijon, France.

E-mail address: xavier.grosmaitre@u-bourgogne.fr (X. Grosmaitre).

1 Present address: Max Planck Research Unit for Neurogenetics, Max-von-LaueStraße 3, D-60438 Frankfurt am Main, Germany.

2 Present address: Team molecular determinants of pain, Institut des Neurosciences Cellulaires et Intégratives (INCI), CNRS UPR3212, 5 Rue Blaise Pascal, F-67084 Strasbourg, France.
}

\section{Introduction}

Olfactory sensory neurons (OSNs) represent the first step of the olfactory system. Located in the olfactory mucosa lining the nasal cavity, they convert the chemical information (i.e. odorant molecules) into an electrical signal that is sent to the brain. The diversity of odorant molecules detected is extremely vast thanks to a very large olfactory receptors' (ORs) repertoire. ORs are G protein-coupled receptors and the vast majority of OSNs rely on the cAMP transduction pathway [33]. This pathway involves activation of olfactory-specific G-protein (Golf), adenylyl cyclase type III (ACIII), and cyclic nucleotide-gated (CNG) channel [20]. In the 
mouse, the repertoire of ORs is encoded by $>1000$ genes [5]. Each individual OSN expresses only one allele of a single OR [8,21,27]. The expression of each OR is restricted to broad, partially overlapping, zones in the olfactory epithelium (OE) [22,24,29,31,35]. Within a zone, different populations of ORs show a multitude of spatial expression patterns, from even antero-posterior distribution to localized peak distribution [4]. The zonal patterning of ORs in the $\mathrm{OE}$ is maintained during normal or lesion-induced neurogenesis $[18,23]$. However, the effects of experience, especially sensory deprivation on the spatial repartition or density of OSNs within a particular zone is unknown.

Exposed to the environment, the olfactory epithelium is continuously regenerated throughout life. OSNs regenerate from dividing basal cells in order to maintain the epithelial homeostasis [for review,see 26]. This continuous regeneration makes the olfactory system prone to activity-dependent development and modulation. To investigate the role of activity-dependent modulation, Unilateral Naris Occlusion (UNO) has been widely used. It induces modifications of sensory inputs into the two nostrils: the closed side deprived of airflow and odor stimulation, while the open side, being the only source of air during breathing, experiences greater strain than the normal airflow and odorant stimulation. UNO has been shown to cause structural, molecular and functional changes in the MOE $[1,2,11,12,14,15,17,30,36-38]$, as well as in higher structures [9][for review see 9]. More specifically, the MOE's activity is modulated by UNO: the closed side showed increased amplitude and slower kinetics in odorant-induced electroolfactogram (EOG) signals as compared with the open side [36]. UNO also alters OR gene expression in both the closed and open sides [11,32] while odorant receptor gene expression is diversely modulated depending on the OR [38]. At the cellular level, UNO induces individual modulation of odorants' induced activity in single OSNs [17]. Since individual OSN's activity is modulated, it is essential to measure molecular changes at the cellular level: does experience modulate gene expression in individual cells and consequently modify functional characteristics of OSNs?

To address this question, we report here the consequences of UNO on two populations of OSNs' expressing defined odorant receptors: MOR23 and M71. Using gene-targeted mice expressing the GFP under the promoter of these receptors, we compared the density of GFP labeled neurons in open, closed and control mice. For the molecular consequences at the cellular level, we harvested dissociated GFP labeled cells and quantify the mRNA levels for transduction pathway proteins. We conclude that experience induced plasticity will have different effects on different OSNs' population.

\section{Material and methods}

\subsection{Animals}

Gene targeted MOR23-IRES-tauGFP mice and M71-IRES-tauGFP were used to monitor respectively the MOR23 and M71 neurons $[3,34]$. Animals were allowed access to food (A04 diet, Safe, France) and water ad libitum and were kept on a $12 \mathrm{~h}$ light/dark cycle, with a $22{ }^{\circ} \mathrm{C}$ constant temperature. All experiments were carried out in accordance with the European Union Directive (Dir. 2010/63/UE) and resulting French regulations. Accordingly, all experimental protocols were approved by the Université de Bourgogne ethic committee.

\subsection{Naris occlusion}

On the second day after birth, mice were anesthetized by hypothermia. Unilateral naris occlusion (UNO) was performed by cauterization using a low temperature cauterizer (Fine Science Tools, Foster City, CA, USA). Pups were then placed on a heating plate until they recover from anesthesia. Lidocain $5 \%$ was deposited on the scar before returning the pup to their home cage. Mice (males and females) were examined 3 weeks later by visual inspection under a stereo microscope. Only mice with successful occlusion were used for further analysis, with age-matched untreated mice as control.

\subsection{Tissue harvesting}

On postnatal day 21, mice were deeply anesthetized by injection of ketamine $\mathrm{HCl}$ and xylazine $(150 \mathrm{mg} / \mathrm{kg}$ and $10 \mathrm{mg} / \mathrm{kg}$ body weight, respectively), and then decapitated. The head was immersed in cold ACSF solution, which contained (in $\mathrm{mM}$ ): $\mathrm{NaCl}$ $124, \mathrm{KCl} 3, \mathrm{MgSO}_{4} 1.3, \mathrm{CaCl}_{2} 2, \mathrm{NaHCO}_{3} 26, \mathrm{NaH}_{2} \mathrm{PO}_{4}$ 1.25, glucose 15; pH 7.6 and 305 mOsm. The olfactory mucosa attached to the nasal septum and to the dorsal recess were rapidly removed: mucosa from each nostril was used either for qPCR analysis or flat mount preparation. Both sides from each animal were not necessarily used for the same experiments: i.e. for cell dissociation only one side per mouse was used, the other side was either used for flat mount or discarded.

\subsection{Flat mount preparation and OSNs counting}

These experiments were implemented as described in [6]. Briefly, harvested epithelia were fixed with PFA 4\% in PBS, mounted, and visualized using a GFP filter (BP460-490) equipped upright microscope. Images covering the entire epithelium were taken and assembled to reconstitute the whole tissue in a unique picture. The neuronal density was then calculated as the ratio of the number of GFP+ neurons against the surface identified as the area including all visible GFP+ neurons.

\subsection{Dissociation and cell collection for molecular biology}

These experiments were carried out as published earlier [6]. Briefly, olfactory epithelia were enzymatically and mechanically dissociated; then cells were allowed to settle and attach to polyethylenimine coated glass and washed. Single GFP cells were collected under fluorescent light with borosilicate glass pipette. Collected OSNs were placed in $3 \mu \mathrm{l}$ lysis and stabilization buffer prior to storage at $-80^{\circ} \mathrm{C} .1 \mu \mathrm{l}$ of medium is collected as negative control.

For preparation of cDNA, all processes were carried out in one tube to minimize sample loss. Samples were treated with $0.2 \mathrm{U}$ Shrimp Dnase and heated to $37^{\circ} \mathrm{C}$ for $10 \mathrm{~min}$. Reverse transcription (RT) was carried out using $115 \mathrm{U}$ of Superscript III reverse transcriptase (Invitrogen) and random hexamers.

qPCR were performed as previously published [6]. The following gene-specific primers were designed with Primer express 3.0 software and their specificities analyzed using Primer-Blast: Olfr16: forward: 5' CTTGTTGGTTTGTGGGTCTTTAGG 3', reverse: 5' CAAAAGGGCAAATGGAACATG 3'; Olfr151: foward: $5^{\prime}$ CCATCTGTCAACCCTTGCTTTAT 3'; reverse: 5' TCAACATGAGGCCAGTCTCAAT 3'; ACIII: forward: 5' AGGCGACTGTTACTACTGCATCTG $3^{\prime}$, reverse: $5^{\prime}$ ACGTACGAGATGGCCTCTACCA 3'; Cnga2: forward: 5' GGCACCAAAAAGAAATTTGAACTG 3', reverse: 5' CAGGCTCTGGCTACCAACAGA 3'; Pde1c: forward: 5' GTCCCAGCGTCGTGATTAGC 3', reverse: 5' TCATGACATCTCGAGCAAGTCTTT 3'; Gapdh: forward: 5' CCTGGAGAAACCTGCCAAGTAT 3', reverse: 5' CTGTTGAAGTCGCAGGAGACAA 3'

The relative expression levels of genes of interest were analyzed using $2^{-\Delta \Delta \mathrm{Ct}}$ method by normalization with GAPDH gene expres- 


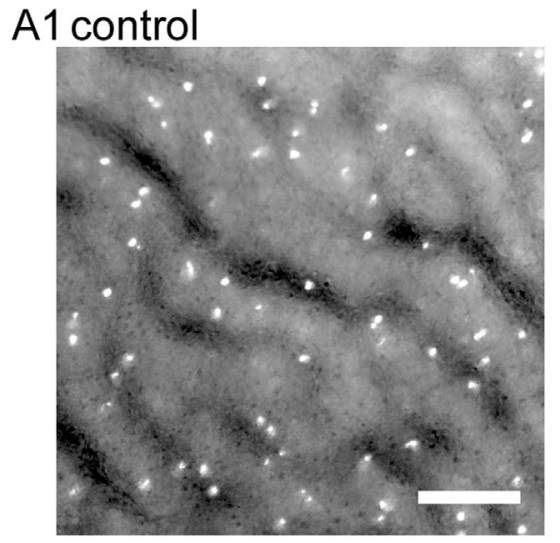

A2 open

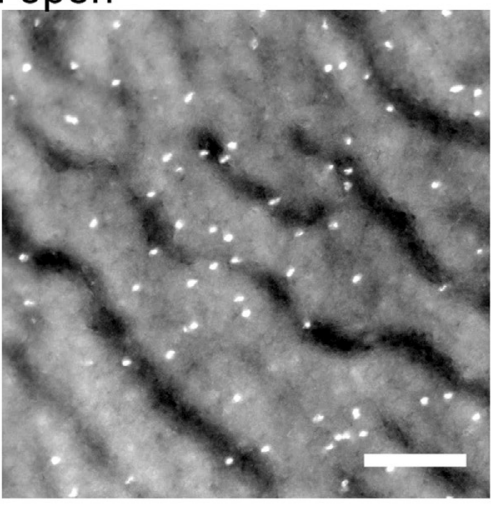

B1

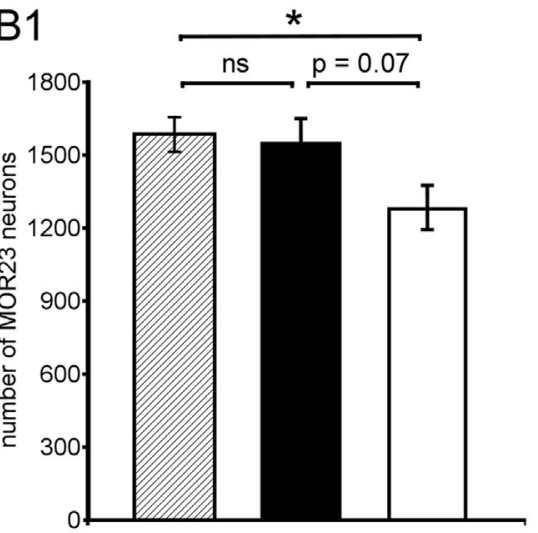

B2

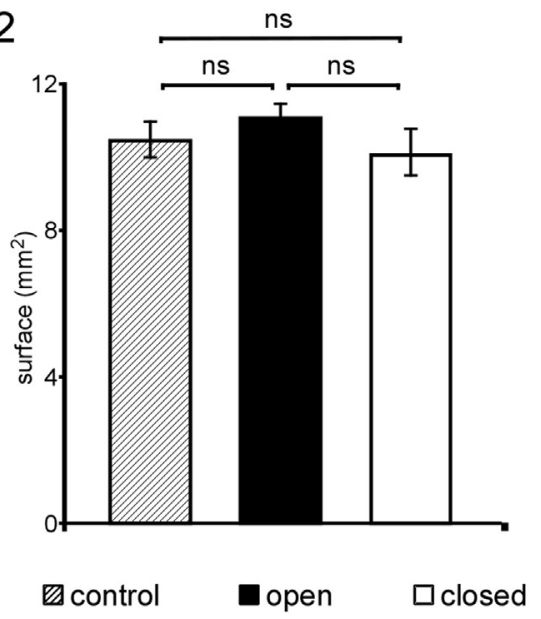

A3 closed

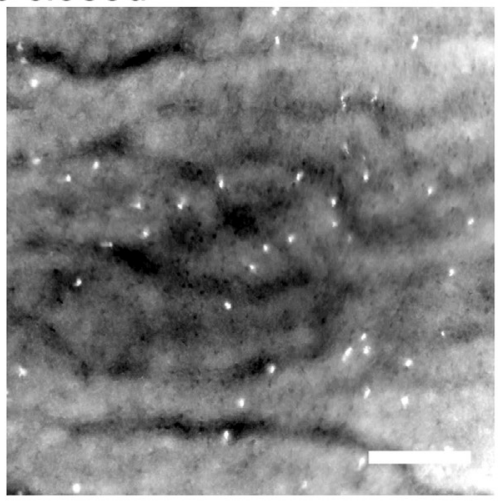

B3

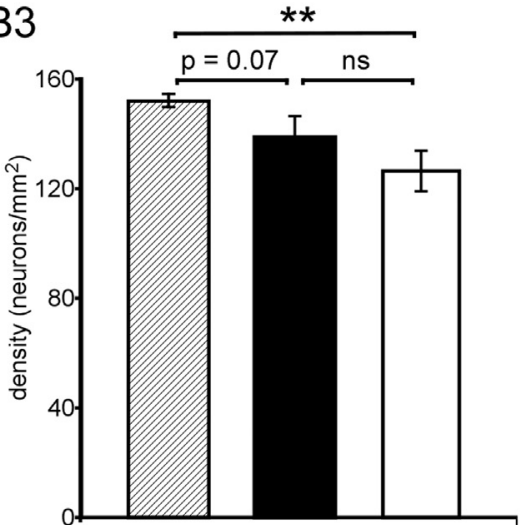

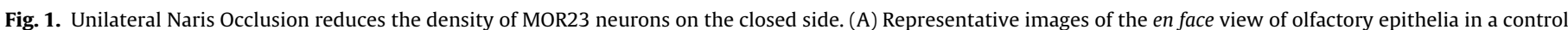

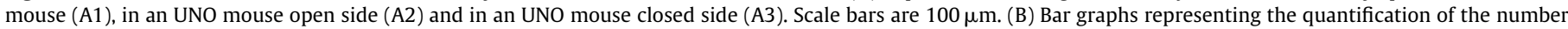

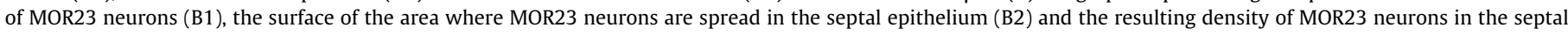

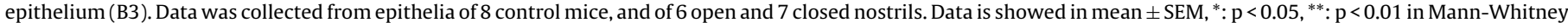
$U$ test following a significant $(\mathrm{p}<0.05)$ Kolmogorov-Smirnov test.

sion and presented as relative quantity (RQ) compared with control group.

Statistical analysis: non-parametric Kolmogorov-Smirnov (KS) tests followed by Mann-Whitney (MW) $U$ tests for two independent samples were performed using Origin software (OriginLabs).

\section{Results}

\subsection{Unilateral Naris Occlusion impacts the density of MOR23 but} not of M71 neurons in the open side

We measured the anatomical consequences of naris closure on populations of OSNs expressing defined odorant receptors: MOR23 and M71. In the dorsal recess and septal epithelium we quantified the number of GFP positive (GFP+) neurons, the surface of the area where the GFP+ neurons are located and calculated the resulting density of GFP+ neurons. We compared control epithelia to epithelia originating from open and closed nasal cavities. Open and closed nasal epithelia did not necessarily come from the same animals.

In MOR23 mice, we analyzed the epithelia of 8 control mice and of 6 open and 7 closed nostrils (Fig. 1A). In the area of interest, the number of MOR23 neurons was similar in control conditions compared to open nostrils while it dropped in closed nostrils. Control and closed conditions were significantly different: control vs closed: $\mathrm{Z}=1.41, \mathrm{p}=0.02 \mathrm{KS}$ test; $\mathrm{Z}=2.26, \mathrm{p}=0.02 \mathrm{MW} U$ test. The surface containing MOR23-GFP neurons did not change between control and open or closed conditions (Fig. 1B2). Consequently,
UNO induced a decrease in the MOR23 neurons' density in the closed nostril compared to the control condition (Ctrl vs closed: $\mathrm{Z}=1.41, \mathrm{p}=0.02 \mathrm{KS}$ test; $\mathrm{Z}=2.72, \mathrm{p}=0.006 \mathrm{MW} U$ test, Fig. 1B3). Meanwhile, the open side reveals a density at intermediate level between control and closed side.

In summary: in MOR23 mice, UNO induced changes in the number of neurons as well as the density of MOR23 neurons in the closed side respect to control.

In M71 mice, we analyzed the epithelia of 8 control mice and of 5 open and 5 closed nostrils (Fig. 2). In the area of interest, UNO induced a slight decrease yet not significant in the number of M71 OSNs both in open and closed sides compared to control animals (Fig. 2B1). The surface decreased between control and open epithelia $(Z=1.4, p=0.02$, KS test; $Z=2.27, p=0.02$ MW $U$ test, Fig. 2B2). Meanwhile the surface of the closed epithelia exhibited an intermediate value different neither from control nor open side. Since both number and surface decreased, the density of M71 neurons did not change between control and open or closed epithelia (Fig. 2B3).

In summary, in M71 mice, UNO did not induce any change in the density of M71 neurons in the open and closed naris respect to control.

\subsection{Unilateral Naris Occlusion impacts the level of expression of transduction pathway proteins in individual neurons}

We measured the molecular consequences of naris closure on two populations of OSNs expressing defined odorant receptors: 

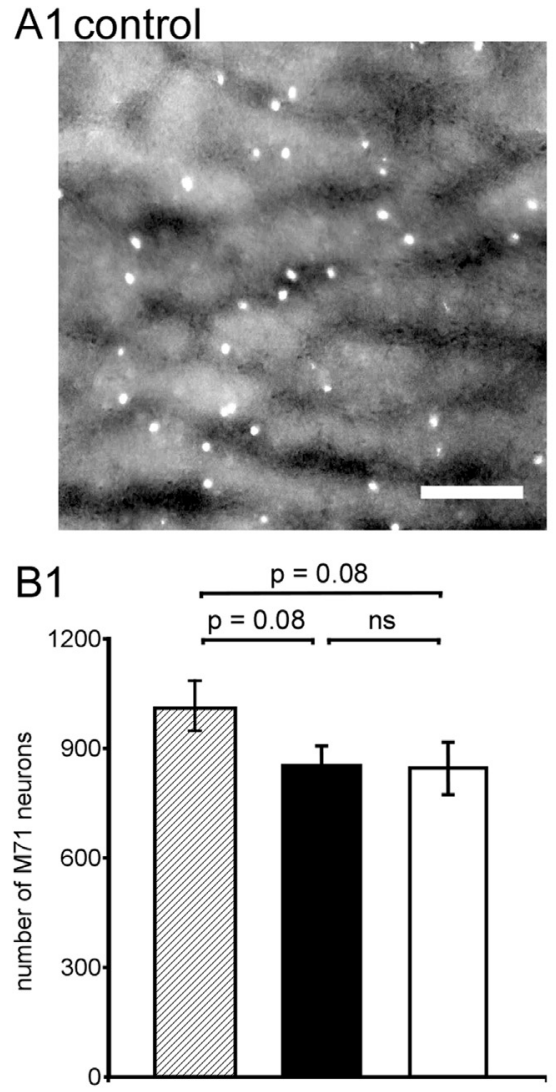

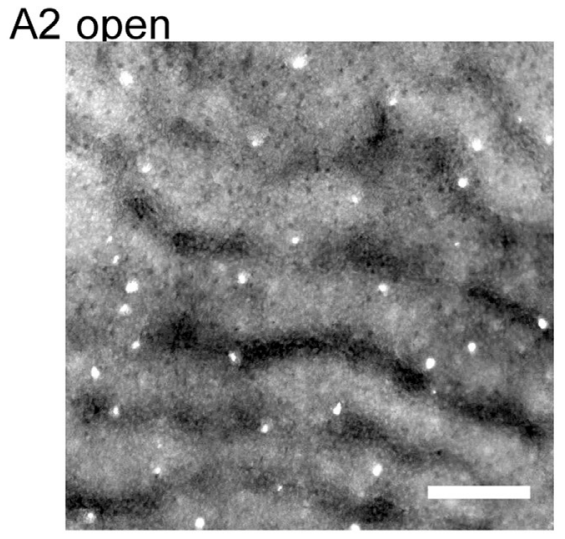

B2

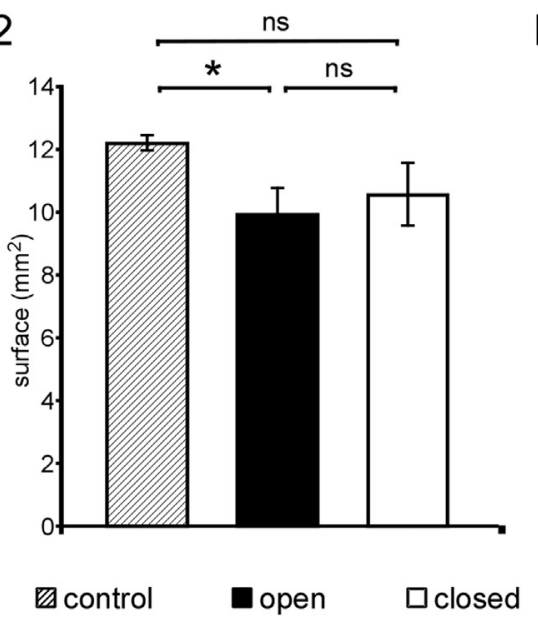

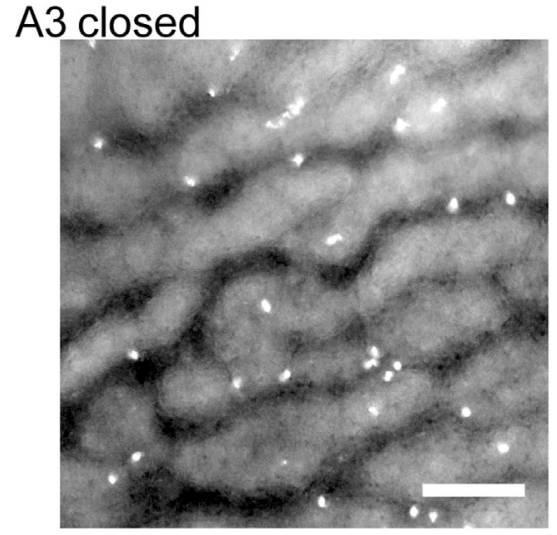

B3

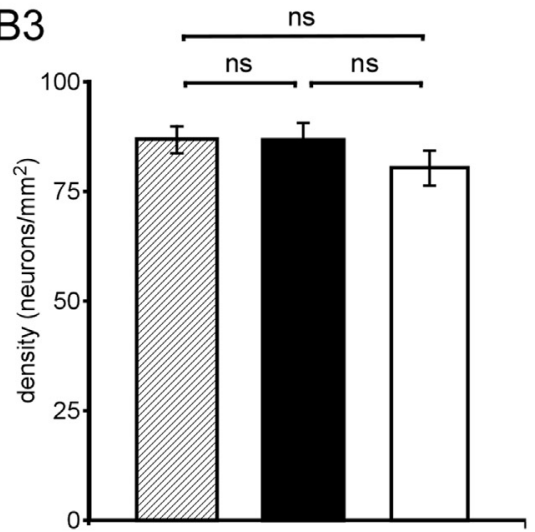

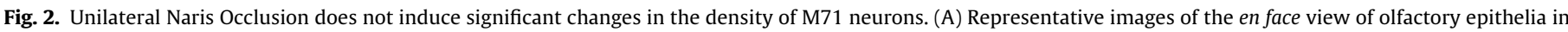

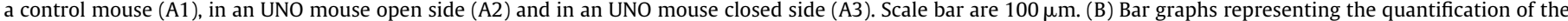

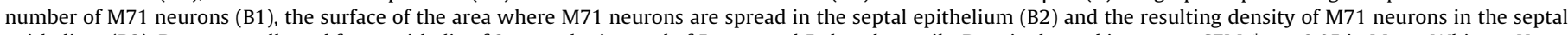

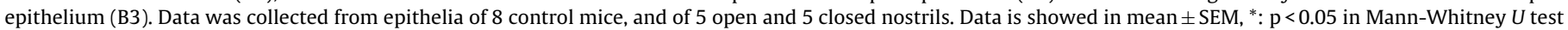
following a significant $(\mathrm{p}<0.05)$ Kolmogorov-Smirnov test.

MOR23 and M71. For this purpose, we used a method developed earlier [6]: olfactory epithelia of control, open and closed nasal cavities were dissociated. Open and closed nasal epithelia did not necessarily come from the same animals. For each epithelium, 5 GFP+ neurons were harvested and pooled. Transcript levels for olfactory receptor (MOR23 or M71), cyclic nucleotide gated channel (CNGA2), adenylate cyclase III (ACIII) and phosphodiesterase 1C (PDE1C) were analyzed.

Effect of naris occlusion on MOR23 neurons: transcript levels were analyzed in neurons from control $(n=12)$, open $(n=6)$ and closed $(n=5)$ epithelia (Fig. $3 A$ ). UNO reduced the transcripts levels of MOR23 in the closed side compared to control ( $p=0.05 \mathrm{KS}$ test, $\mathrm{p}=0.01 \mathrm{MW} U$ test), while the opened side was intermediary and did differ neither from control nor from closed side. The level of CNGA2 was strongly reduced in open side compared to closed side $(\mathrm{p}=0.047 \mathrm{KS}$ test, $\mathrm{p}=0.02$, MW $U$ test $)$ and to control $(\mathrm{p}=0.015 \mathrm{KS}$ test, $\mathrm{p}=0.02 \mathrm{MW} U$ test). The levels of PDE1c in control side did differ neither from open side nor from closed side. The transcript levels of ACIII remained similar in closed side compared to control; meanwhile, the transcript levels of ACIII in open side show a slight yet not significant reduction compared to control side ( $p=0.13 \mathrm{KS}$ test, $\mathrm{p}=0.08 \mathrm{MW} U$ test).

In summary: in MOR23 neurons unilateral naris occlusion induced a reduction of MOR23 receptor transcripts' levels in the closed side compared to control and a reduction of CNGA2 transcript levels in the open side.

Effect of naris occlusion on M71 neurons: transcript levels were analyzed in neurons from control $(n=7)$, open $(n=4)$ and closed $(n=4)$ epithelia (Fig. 3B). UNO did not affect the level of M71 odorant receptor in neither open side nor closed side compared to control. UNO induced a decrease of PDE1c transcripts in the closed side compared to control ( $\mathrm{p}=0.03 \mathrm{KS}$-test, $\mathrm{p}=0.03 \mathrm{MW} U$ test), while there was no difference between open side and control. UNO reduced the CNGA2 levels in the open side compared to control ( $\mathrm{p}=0.06 \mathrm{KS}$-test, $\mathrm{p}=0.047 \mathrm{MW} U$ test), while there is no effect on the closed side ( $\mathrm{p}=0.77$ vs control). ACIII levels in the closed side are slightly reduced compared to control however they failed to reach significant levels ( $\mathrm{p}=0.12 \mathrm{KS}$-test, $\mathrm{p}=0.04 \mathrm{MW} U$ test).

In summary: in M71 neurons, UNO affects levels of PDE1c in the closed side and CNGA2 in the open side respect to control.

\section{Discussion}

Postnatal experience shapes the structures and functional properties of the olfactory epithelium [9,17]. UNO modulates the activity and anatomy of the deprived side, from the MOE to the OB. During development, UNO also disrupts the morphology of the opened nasal cavity [10]: this may impact the surface, thickness as well as the molecular properties of the mucosa and explain the surface changes observed in M71 mice (Fig. 2). In the closed side, a general reduction of the number of OSNs is observed [9]. However, at the level of the individual populations expressing defined ORs, the results are more balanced with increase in the number of neurons of some populations and decrease of others [7,13,38]. Here, by counting the GFP labeled cells in two gene-targeted strains, we confirm that changes induced by UNO are different depending on the 
A: transcript levels in MOR23 neurons
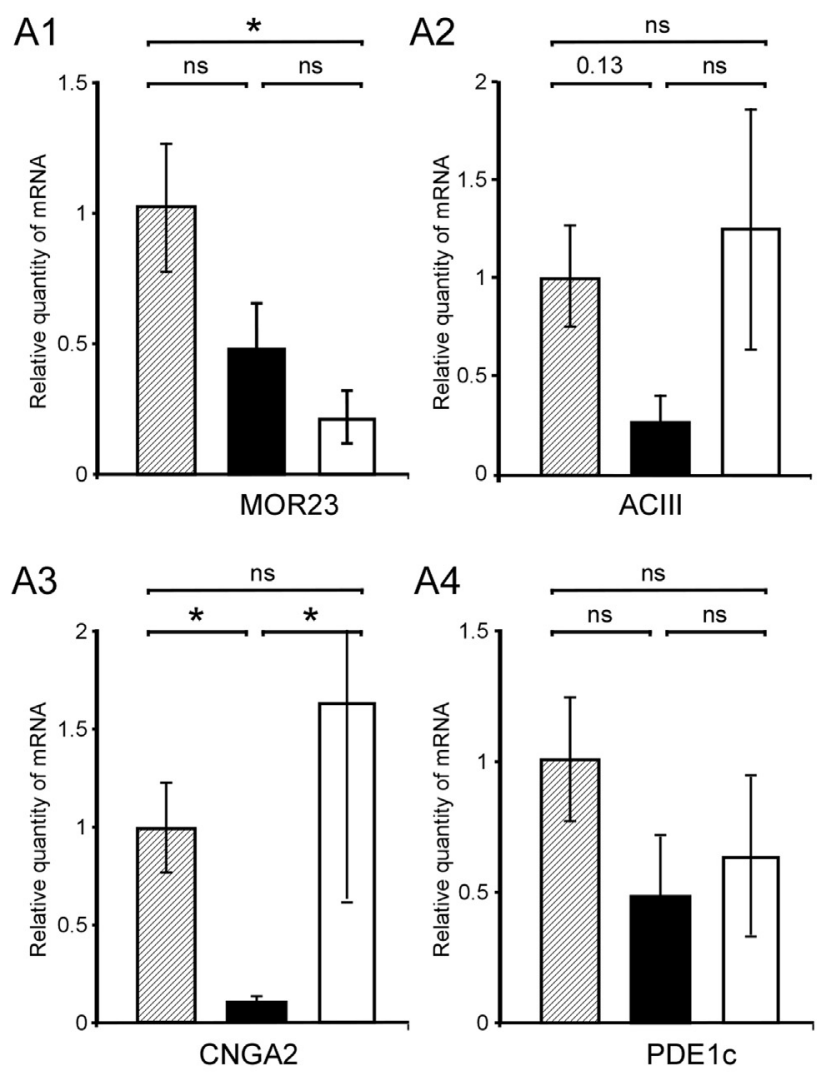

尚 control

\section{B: transcript levels in M71 neurons}
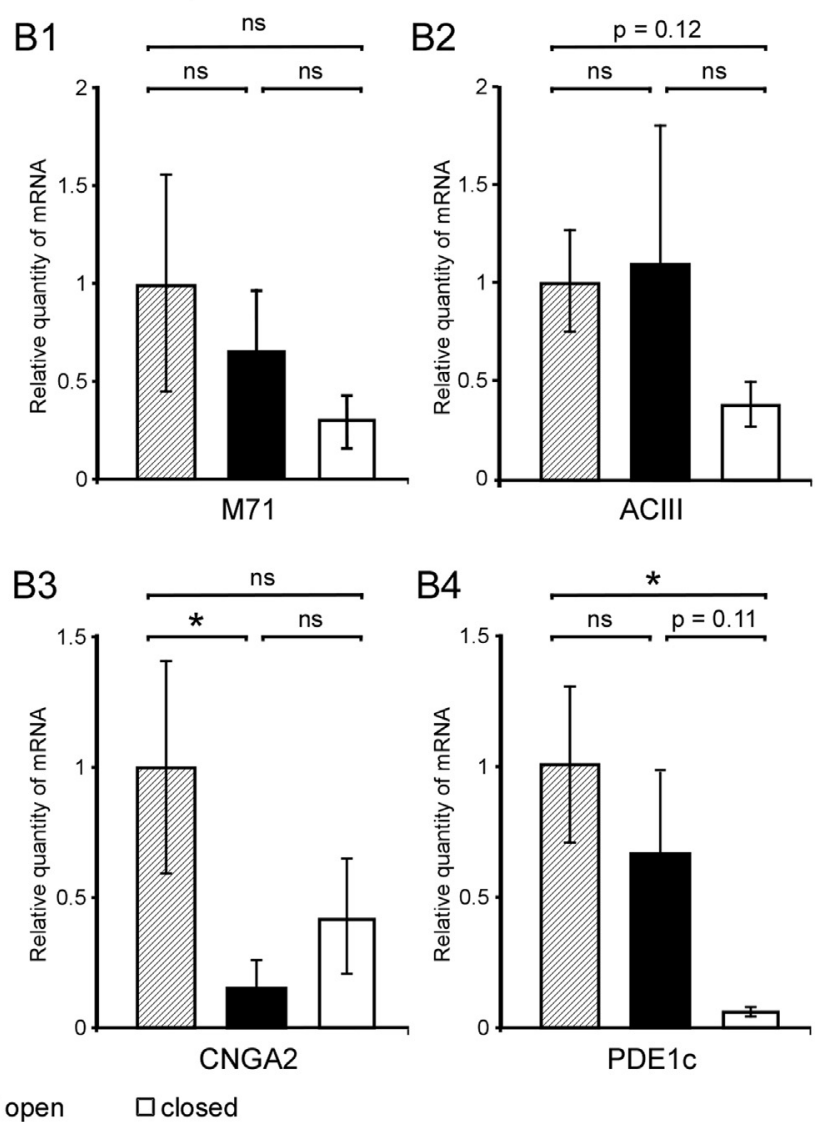

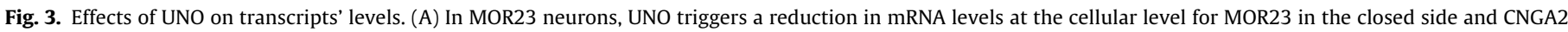

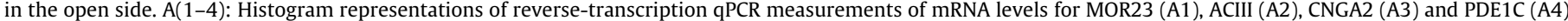

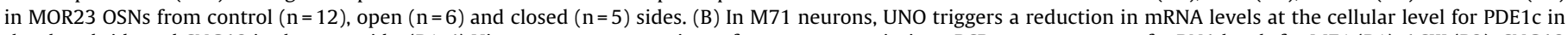

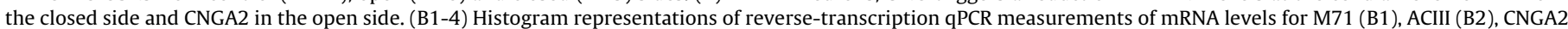

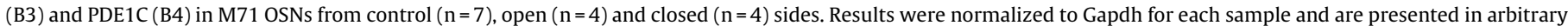
units; the values obtained for control sides were set at $1 .{ }^{*} \mathrm{p}<0.05$; ns, not significant; error bars indicate SEM.

population observed: while the M71 population appears unaffected (Fig. 2), the density of MOR23 neurons is reduced in the closed side (Fig. 1). These differences in the experience induced plasticity may be due to different roles of these OR during the postnatal development. Some ORs are more involved in mother-pups interactions while others will be more important at the adult age for instance for food foraging or partner finding. Consequently, the effects of sensory deprivation may differ from an OR population to another.

At the level of the entire epithelium, UNO causes an ipsilateral increase in olfactory-transduction-cascade transcripts $[11,38]$. At the cellular level, we show here that activity-dependent modulation varies depending on the OSN population: MOR23 neurons from closed sides show lower transcripts for the MOR23 receptor, while CNGA2 transcripts levels are lower in the open side (Fig. 3A); in M71 neurons the level of CNGA2 transcripts is also lower in the open side while PDE1c levels are lower in the closed side (Fig. 3B). Interestingly, in our experimental setup, we did not observe any increase of any transcript at the cellular levels, while some ORs' and transduction pathway proteins' mRNA levels increased in the closed side at the entire epithelium levels [11]. This discrepancy may be due to diversity of effects of UNO depending on the population observed, as shown previously on several lines by in situ hybridization [38]. Our results confirm that activity dependent modulation of gene expression will vary from population to population depending on the OR expressed. Furthermore, our results show that these variations will take place at the cellular level for several genes involved in the transduction pathway. In our experimental setup, large inter-individual variations of transcripts levels were seen. These variations might be due to the intrinsic rhythm of mRNA production: gene expression is non-linear and takes place in bursts, meanwhile all cells are not synchronized in their mRNA production [28]. Recent higher throughput techniques such as single-cell RNAseq $[16,19,25]$ performed on a larger group of cells could be used to confirm our results.

What are the functional consequences of UNO on OSNs? The closed side showed increased amplitude and slower kinetics in odorant-induced electroolfactogram (EOG) signals as compared with the open side [36]. These global functional modifications are associated with the molecular changes at the tissue level. At the cellular levels, patch-clamp recordings show changes in the kinetics of the odorant responses: in response to the cognate ligand of their receptor, both MOR23 and M71 neurons exhibit faster onset in the open side and slower end of the response in the closed side [17]. Our results show that PDE1c is downregulated in the closed side of M71 neurons (Fig. 3B): since PDE1c is involved in the degradation of cAMP levels and therefore the extinction of the response, this downregulation could, in part, explain the longer responses observed in the closed side. Here the level of PDE1c is consistent with the functional properties of the OSNs. However, this consistency falls short in the case of CNGA2: we observed that CNGA2 is downregulated in the open side of both MOR23 and M71 while the responses of M71 neurons are faster and responses of MOR23 
neurons are unchanged [17]. Several other proteins that we did not investigate, such as Golf or Calcium-gated chloride channels, are involved in the onset of the response and could be modulated in a different direction. Finally, the levels of MOR23 receptors are decreased in the closed side (Fig. 3A) which seems consistent with a lower sensitivity of MOR23 neurons. Again, higher throughput techniques may help in the future to bring forward results for more proteins and consistency with functional data.

Conclusion: UNO can influence the properties of individual OSNs through the modulation of transduction pathway proteins' transcript levels. UNO effects on both neuronal density and transcripts levels will vary depending on the OR expressed: experience driven plasticity, similarly to odorant induced plasticity [6] is therefore highly OR dependent.

\section{Author contributions}

Designed Research: X.G.; Performed experiments: all authors; Analyzed data: I.A., A.M., X.G.; Writing - Original Draft: A.M., I.A. and X.G.; Writing - Review and Editing: all authors; Supervision: X.G.; Funding Acquisition: X.G.

\section{Competing financial interests}

The authors declare no competing financial interests.

\section{Acknowledgements}

Authors would like to thank Professor Peter Mombaerts for the gift of MOR23 and M71 mice; Anne Lefranc and the CSGA animal facility for excellent animal care. Funding was provided to XG by CNRS through an ATIP and ATIP Plus grant, by Conseil Régional de Bourgogne (FABER and PARI grants). AM received a postdoctoral fellowship through a FEDER grant. IA received a doctoral fellowship from E2S graduate program from Université de Bourgogne.

\section{References}

[1] M.K. Bennett, H.M. Kulaga, R.R. Reed, Odor-evoked gene regulation and visualization in olfactory receptor neurons, Mol. Cell. Neurosci. 43 (2010) 353-362.

[2] T.E. Benson, D.K. Ryugo, J.W. Hinds, Effects of sensory deprivation on the developing mouse olfactory system: a light and electron microscopic morphometric analysis, J. Neurosci. 4 (1984) 638-653.

[3] T. Bozza, P. Feinstein, C. Zheng, P. Mombaerts, Odorant receptor expression defines functional units in the mouse olfactory system, J. Neurosci. 22 (2002) 3033-3043

[4] O.C. Bressel, M. Khan, P. Mombaerts, Linear correlation between the number of olfactory sensory neurons expressing a given mouse odorant receptor gen and the total volume of the corresponding glomeruli in the olfactory bulb, J. Comp. Neurol. 524 (2016) 199-209.

[5] L. Buck, R. Axel, A novel multigene family may encode odorant receptors: a molecular basis for odor recognition, Cell 65 (1991) 175-187.

[6] H. Cadiou, I. Aoude, B. Tazir, A. Molinas, C. Fenech, N. Meunier, X. Grosmaitre, Postnatal odorant exposure induces peripheral olfactory plasticity at the cellular level, J. Neurosci. 34 (2014) 4857-4870.

[7] M.A. Cavallin, K. Powell, K.C. Biju, D.A. Fadool, State-dependent sculpting of olfactory sensory neurons is attributed to sensory enrichment, odor deprivation, and aging, Neurosci. Lett. 483 (2010) 90-95.

[8] A. Chess, I. Simon, H. Cedar, R. Axel, Allelic inactivation regulates olfactory receptor gene expression, Cell 78 (1994) 823-834.

[9] D.M. Coppola, Studies of olfactory system neural plasticity: the contribution of the unilateral naris occlusion technique, Neural. Plast. 2012 (2012) 351752.

[10] D.M. Coppola, B.A. Craven, J. Seeger, E. Weiler, The effects of naris occlusion on mouse nasal turbinate development, J. Exp. Biol. 217 (2014) 2044-2052.
[11] D.M. Coppola, C.T. Waggener, The effects of unilateral naris occlusion on gene expression profiles in mouse olfactory mucosa, J. Mol. Neurosci. 47 (2012) 604-618.

[12] D.M. Coppola, A.M. Waguespack, M.R. Reems, M.L. Butman, J.A. Cherry, Naris occlusion alters transductory protein immunoreactivity in olfactory epithelium, Histol. Histopathol. 21 (2006) 487-501.

[13] D.M. Cummings, L. Belluscio, Continuous neural plasticity in the olfactory intrabulbar circuitry, J. Neurosci. 30 (2010) 9172-9180.

[14] D.M. Cummings, P.C. Brunjes, Changes in cell proliferation in the developing olfactory epithelium following neonatal unilateral naris occlusion, Exp. Neurol. 128 (1994) 124-128.

[15] A.I. Farbman, P.C. Brunjes, L. Rentfro, J. Michas, S. Ritz, The effect of unilateral naris occlusion on cell dynamics in the developing rat olfactory epithelium, J. Neurosci. 8 (1988) 3290-3295.

[16] N.K. Hanchate, K. Kondoh, Z. Lu, D. Kuang, X. Ye, X. Qiu, L. Pachter, C. Trapnell, L.B. Buck, Single-cell transcriptomics reveals receptor transformations during olfactory neurogenesis, Science 350 (2015) 1251-1255.

[17] J. He, H. Tian, A.C. Lee, M. Ma, Postnatal experience modulates functional properties of mouse olfactory sensory neurons, Eur. J. Neurosci. 36 (2012) 2452-2460.

[18] C.L. Iwema, H. Fang, D.B. Kurtz, S.L. Youngentob, J.E. Schwob, Odorant receptor expression patterns are restored in lesion-recovered rat olfactory epithelium, J. Neurosci. 24 (2004) 356-369.

[19] M. Khan, E. Vaes, P. Mombaerts, Regulation of the probability of mouse odorant receptor gene choice, Cell 147 (2011) 907-921.

[20] S.J. Kleene, The electrochemical basis of odor transduction in vertebrate olfactory cilia, Chem. Sens. 33 (2008) 839-859.

[21] B. Malnic, J. Hirono, T. Sato, L.B. Buck, Combinatorial receptor codes for odors, Cell 96 (1999) 713-723.

[22] K. Miyamichi, S. Serizawa, H.M. Kimura, H. Sakano, Continuous and overlapping expression domains of odorant receptor genes in the olfactory epithelium determine the dorsal/ventral positioning of glomeruli in the olfactory bulb, J. Neurosci. 25 (2005) 3586-3592.

[23] E.M. Norlin, M. Alenius, F. Gussing, M. Hagglund, V. Vedin, S. Bohm, Evidence for gradients of gene expression correlating with zonal topography of the olfactory sensory map, Mol. Cell. Neurosci. 18 (2001) 283-295.

[24] K.J. Ressler, S.L. Sullivan, L.B. Buck, Information coding in the olfactory system: evidence for a stereotyped and highly organized epitope map in the olfactory bulb, Cell 79 (1994) 1245-1255.

[25] P. Scholz, B. Kalbe, F. Jansen, J. Altmueller, C. Becker, J. Mohrhardt, B. Schreiner, G. Gisselmann, H. Hatt, S. Osterloh, Transcriptome analysis of murine olfactory sensory neurons during development using single cell RNA-Seq, Chem. Senses (2016).

[26] J.E. Schwob, Neural regeneration and the peripheral olfactory system, Anat. Rec. 269 (2002) 33-49.

[27] S. Serizawa, K. Miyamichi, H. Nakatani, M. Suzuki, M. Saito, Y. Yoshihara, H. Sakano, Negative feedback regulation ensures the one receptor-one olfactory neuron rule in mouse, Science 302 (2003) 2088-2094.

[28] A. Stahlberg, M. Kubista, The workflow of single-cell expression profiling using quantitative real-time PCR, Exp. Rev. Mol. Diagn. 14 (2014) 323-331.

[29] J. Strotmann, I. Wanner, T. Helfrich, A. Beck, H. Breer, Rostro-caudal patterning of receptor-expressing olfactory neurones in the rat nasal cavity, Cell Tissue Res. 278 (1994) 11-20.

[30] K.S. Suh, S.Y. Kim, Y.C. Bae, G.V. Ronnett, C. Moon, Effects of unilateral naris occlusion on the olfactory epithelium of adult mice, Neuroreport 17 (2006) 1139-1142.

[31] S.L. Sullivan, M.C. Adamson, K.J. Ressler, C.A. Kozak, L.B. Buck, The chromosomal distribution of mouse odorant receptor genes, Proc. Natl. Acad. Sci. U. S. A. 93 (1996) 884-888.

[32] H. Tian, M. Ma, Activity plays a role in eliminating olfactory sensory neurons expressing multiple odorant receptors in the mouse septal organ, Mol. Cell. Neurosci. 38 (2008) 484-488.

[33] K. Touhara, L.B. Vosshall, Sensing odorants and pheromones with chemosensory receptors, Annu. Rev. Physiol. 71 (2009) 307-332.

[34] A. Vassalli, A. Rothman, P. Feinstein, M. Zapotocky, P. Mombaerts, Minigenes impart odorant receptor-specific axon guidance in the olfactory bulb, Neuron 35 (2002) 681-696.

[35] R. Vassar, J. Ngai, R. Axel, Spatial segregation of odorant receptor expression in the mammalian olfactory epithelium, Cell 74 (1993) 309-318.

[36] C.T. Waggener, D.M. Coppola, Naris occlusion alters the electro-olfactogram: evidence for compensatory plasticity in the olfactory system, Neurosci. Lett. 427 (2007) 112-116.

[37] A.M. Waguespack, M.R. Reems, M.L. Butman, J.A. Cherry, D.M. Coppola, Naris occlusion alters olfactory marker protein immunoreactivity in olfactory epithelium, Brain Res. 1044 (2005) 1-7.

[38] S. Zhao, H. Tian, L. Ma, Y. Yuan, C.R. Yu, M. Ma, Activity-dependent modulation of odorant receptor gene expression in the mouse olfactory epithelium, PLoS One 8 (2013) e69862. 